\title{
Patient Height, Weight, BMI and Age as Predictors of Gracilis Muscle Free-Flap Mass in Lower Extremity Reconstruction
}

\author{
CARLO M. ORANGES ${ }^{1}$, MATHIAS TREMP ${ }^{1}$, WENJIN WANG ${ }^{2}$, SRINIVAS MADDURI ${ }^{1,3,4}$, \\ PIETRO G. DI SUMMA ${ }^{5}$, RETO WETTSTEIN ${ }^{1}$, DIRK J. SCHAEFER ${ }^{1}$ and DANIEL F. KALBERMATTEN ${ }^{1}$ \\ ${ }^{1}$ Department of Plastic, Reconstructive, Aesthetic and Hand Surgery, Basel University Hospital, Basel, Switzerland; \\ ${ }^{2}$ Department of Plastic and Reconstructive Surgery, Shanghai Ninth People's Hospital, Shanghai, P.R. China; \\ ${ }^{3}$ Department of Biomedicine, and ${ }^{4}$ Department of Biomedical Engineering, University of Basel, Basel, Switzerland; \\ ${ }^{5}$ Department of Plastic, Reconstructive and Aesthetic Surgery, Lausanne University Hospital, Lausanne, Switzerland
}

\begin{abstract}
Background: Gracilis muscle flap is commonly used for the reconstruction of defects of the lower extremities. Preoperative evaluation of gracilis muscle dimension is a key aspect in surgical planning. This study aimed to determine whether patient height, weight, body mass index (BMI) and age are reliable proxy measurements of the mass of gracilis muscle flap. Patients and Methods: Twenty-two patients treated for lower extremity reconstruction with free gracilis flap between December 2010 and December 2014 were considered. The relationships between the mass of gracilis muscle and patient height, weight, BMI and age were assessed with Pearson's product moment correlation coefficient. Defect size, mass of gracilis muscle resected and surgical outcomes were also evaluated. Results: There was a moderate correlation between the mass of the gracilis muscle and patient height $(r=0.4)$, weight $(r=0.4)$, and BMI $(r=0.3)$, and moderate inverse correlation with age $(r=-0.04)$. Lower extremities defects ranged in size from $3 \times 4 \mathrm{~cm}\left(12 \mathrm{~cm}^{2}\right)$ to $26 \times 11 \mathrm{~cm}\left(286 \mathrm{~cm}^{2}\right)$ with a mean of $81.6 \mathrm{~cm}^{2}$. All defects were reconstructed with the gracilis muscle, which required a resection ranging between $3 \mathrm{~g}$ and $105 \mathrm{~g}$ (mean=37.4 $\mathrm{g}$ ) to adapt the flap to the recipient site. Complete flap loss was observed in one case. Conclusion: In our series, the mass of the gracilis muscle flap was
\end{abstract}

This article is freely accessible online.

Correspondence to: Daniel F. Kalbermatten, MD, Ph.D., Department of Plastic, Reconstructive, Aesthetic, and Hand Surgery, Basel University Hospital, Spitalstrasse 21, 4031 Basel, Switzerland. Tel: +41 612652525, Fax: +41 612657301, e-mail: daniel.kalbermatten@usb.ch

Key Words: Height, weight, BMI, age, muscle mass predictors, lower extremity reconstruction, gracilis muscle, free flap. predictable in relation to height, weight, BMI, and age, which can be considered reliable proxy measurements. This will contribute to adequate flap selection for microsurgical reconstruction of lower extremity defects.

The use of the gracilis muscle as a free flap was first introduced in reconstructive surgery by Harii and colleagues in 1976 (1). It is mainly indicated for head and neck reconstruction (2), treatment of facial paralysis (3) and reconstruction of the extremities (4). A pedicled flap can also be used for perineal (5) and genital reconstruction (6). If required by the reconstructive plan, the flap can be harvested with a skin paddle. A variant with a transversely oriented proximal skin paddle was described by Youssif in 1992 (7, 8), and applied as transverse myocutaneous gracilis flap for breast reconstruction by Arnez et al. in 2004 (9). One of the advantages offered by this muscle flap is its well-hidden donor site, especially in those cases when it is harvested using a groin (10) incision or through an endoscopic access. Moreover, a 'secret scar' technique without skin graft mark for lower extremity reconstruction was recently described by Tremp et al. (11) In this technique, the gracilis flap is harvested using a horizontally oriented wedge-shaped excision of the inguinal skin and subcutaneous tissues.

The ability to predict the mass of gracilis muscle preoperatively is essential in order to understand if the flap can be selected as valid reconstructive option for the injured area. The aim of the present study was to verify whether the gracilis muscle mass is proportional to patient height, weight, body mass index (BMI) and age, and if these variables could therefore be used as proxy measurements. We tested this hypothesis in the case of lower extremity reconstruction. We also wanted to verify the actual relationship between the gracilis muscle flap and the area of the lower extremity to be reconstructed in terms of adequate coverage, and the efficacy of the microsurgical reconstruction. 

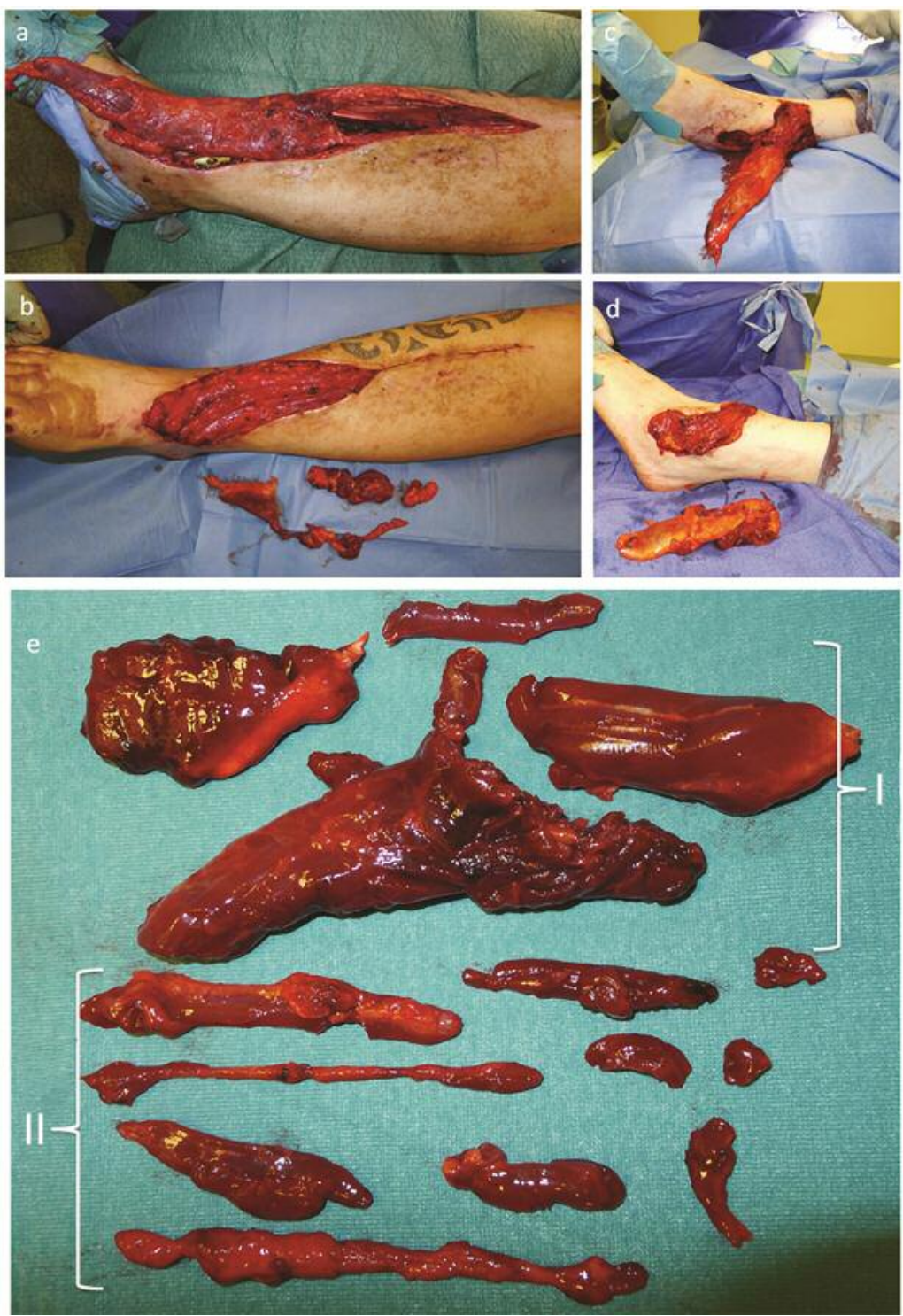

Figure 1. Gracilis muscle free flap used for lower extremity reconstruction ( $a, b$, lower leg; $c, d$, foot). The excess of muscle is resected to adapt the flap to the defect area $(b, d)$ in large $(e I)$ or small fragments (e II).

\section{Patients and Methods}

The data were collected from all patients undergoing lower extremity reconstruction with gracilis free flap during the 4-year period between December 2010 and December 2014. The 'secret scar' technique was followed for free flap harvesting (11). Patient height, weight, BMI and age were recorded, as well as diagnosis, location and dimension of the injury on the lower extremity. The efficacy of the reconstruction and microsurgical complications, such as flap loss or anastomosis revision, were also collected. The mass of the gracilis muscle flap and the mass of the part of the flap removed in order to properly fill the defect area were measured intraoperatively (Figure 1).
The correlation between each continuous variable (patient height, weight, BMI, age) and gracilis muscle mass was examined by applying the Pearson product moment correlation test. Statistical significance was determined by a value of $p \leq 0.05$ for all tests. Analyses were performed using Excel 2010 (Microsoft Corporation - Seattle, WA, USA). Written consent was obtained from all patients, and the guidelines of the Declaration of Helsinki were followed.

\section{Results}

A total of 22 patients affected by lower extremity defects were included. The indications for reconstruction were 


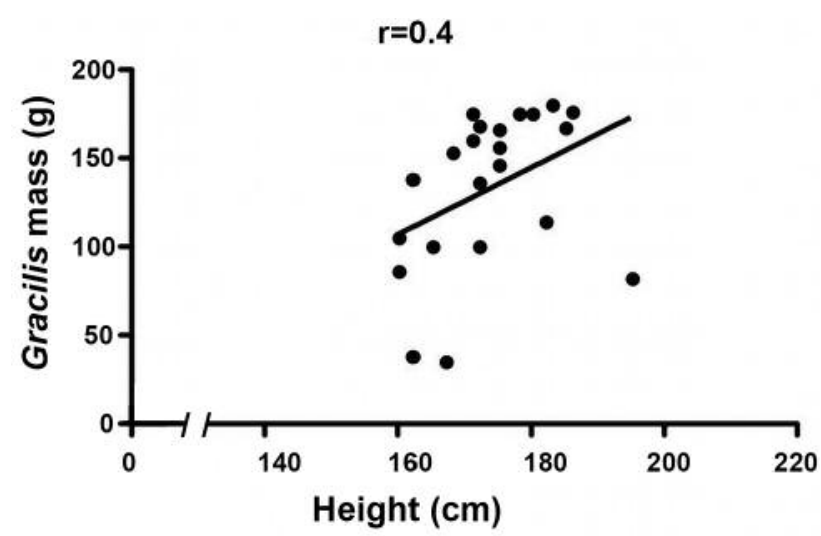

Figure 2. Plot of gracilis muscle mass versus patient height. A moderate correlation between the variables is shown $(r=0.4, p=0.07)$.

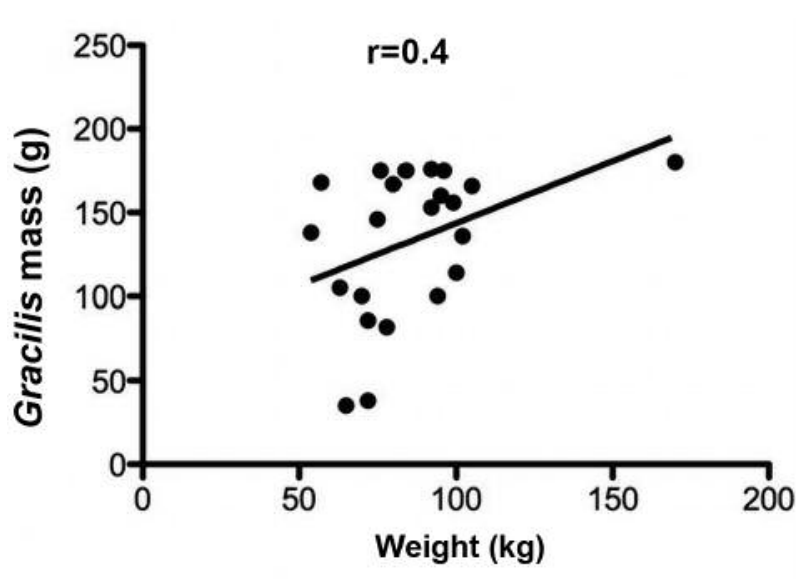

Figure 3. Plot of gracilis muscle mass versus patient weight. A moderate correlation between the variables is shown $(r=0.4, p=0.06)$.

osteomyelitis in 10 patients, fractures in 11 patients, and soft tissue defect after tumor resection in one patient. The mean patient age was 50.8 (range $=28-71$ ) years. Nine were female and 13 were male. The reconstructed areas were: lower leg in nine cases, ankle in nine cases, feet in three cases, and knee in one case. The mean reconstructed defect area was $81.6 \mathrm{~cm}^{2}$, with a size ranging between $3 \times 4 \mathrm{~cm}$ $\left(12 \mathrm{~cm}^{2}\right)$ and $26 \times 11 \mathrm{~cm}\left(286 \mathrm{~cm}^{2}\right)$. The mean mass of the gracilis muscle was $133.2 \mathrm{~g}$ (range $=35-180 \mathrm{~g}$ ). The mean mass of the part of the gracilis muscle resected was $37.4 \mathrm{~g}$ (range $=3-105 \mathrm{~g}$ ). In all cases, the flap presented a mass adequate to reconstruct the lesion. Anastomoses were performed on anterior tibilialis vessels in half of the cases

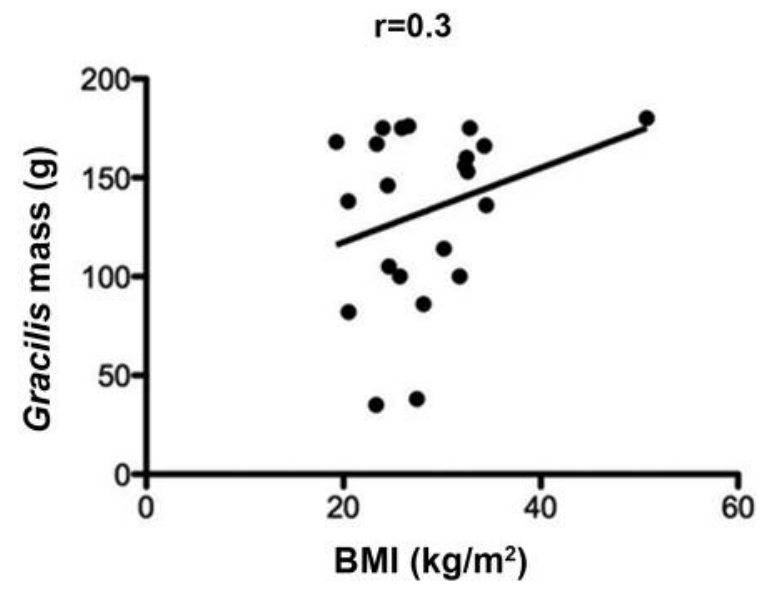

Figure 4. Plot of gracilis muscle mass versus body mass index (BMI). A moderate correlation between the variables is shown $(r=0.3, p=0.19)$.

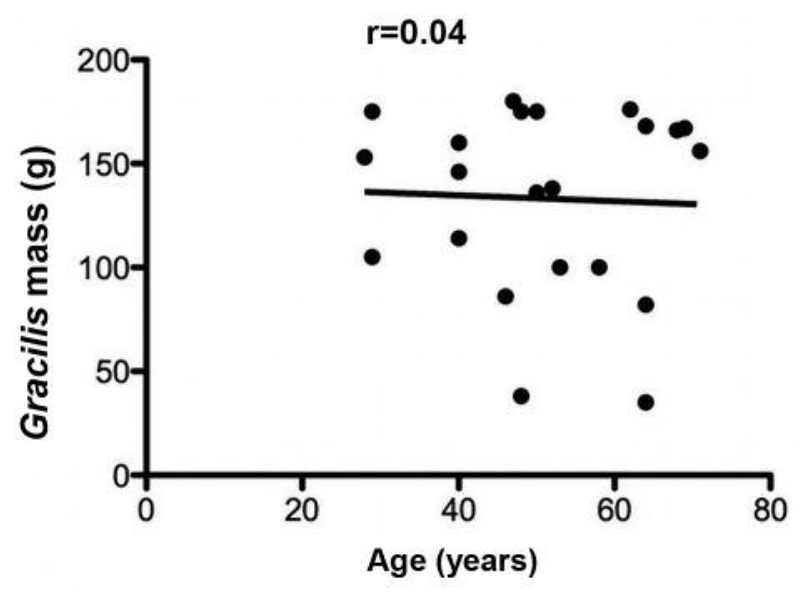

Figure 5. Plot of gracilis muscle mass versus age. A moderate negative correlation between the variables is shown $(r=-0.04, p=0.86)$.

and on posterior tibialis vessels in the remaining half. Endto-end anastomoses were performed in 15 cases and endto-site in seven cases. In one case, end-to-end anastomosis was performed with a loop. Revision of anastomosis was needed in one case with complete flap loss after 3 days due to thrombosis.

Using the Pearson product moment correlation, moderate correlation of height ( $\mathrm{r}=0.4, p=0.07$; Figure 2$)$ and weight of the patient with gracilis muscle mass was found $(\mathrm{r}=0.4$, $p=0.06$; Figure 3 ). Similarly, there was a moderate correlation between gracilis mass and BMI $(\mathrm{r}=0.3 ; p=0.19$; Figure 4), and moderate negative correlation with age $(\mathrm{r}=-0.04 ; p=0.86$; Figure 5$)$. 


\section{Discussion}

Gracilis, latissimus dorsi and rectus abdominis muscle free flaps are the most commonly used options for lower extremity reconstruction when free soft-tissue transfer is needed. Each flap presents its own specific advantages, disadvantages and indications (12). Rectus abdominis and latissimus dorsi are normally used when a great amount of tissue is required but can be affected by higher level of complication at the donor site (13). Use of a gracilis flap is a good option when a smaller amount of soft tissue is required and its donor site morbidity is minimal $(12,14)$. Therefore, being able to predict the dimension of the gracilis can be useful in decision making.

This study suggested patient height, weight, BMI and age as proxy measurements for gracilis muscle mass according to a similar investigation performed in the field of microsurgery (15), and to the knowledge available in the field of forensic anthropology, which elaborated formulae to estimate height from anthropometric data such as long bone length (femur/tibia/humerus), assuming that skeletal relationships are proportional (15-18). We were, indeed, able to confirm from our group of patients the assumption that taller patients, with higher BMI, tend to have higher gracilis muscle mass, with a moderate correlation.

Notably, whole-body and regional measurements were integrated into existing body composition paradigms by several previous investigations [reviewed in (19)]. Webster et al. in 1983 demonstrated that fat mass adjusted for height, and consequently the fat-free mass index, is strongly correlated with BMI (20). Accordingly, they proposed a stable composition of "excess weight" to be equal to about one fourth fat-free mass and observed that lean mass and skeletal muscle increase as adiposity increases (20). These observations were confirmed by our results, which showed a moderate direct correlation between patient weight and gracilis muscle mass. Moreover, our results were also in accord with the Forbes' 'companionship' rule that postulates a curvilinear relationship between fat-free mass and total body fat, with relatively large gains or loss of fat-free mass with changes in the energy balance at low levels of an individual's adiposity $(19,21)$.

However, it was reported that obesity and aging are responsible for intramuscular fat accumulation in skeletal muscle tissue $(22,23)$. Therefore, in patients with higher BMI, larger muscle mass results from both an increase of lean mass and deposition of intramuscular fat (24). Nevertheless, this does not represent a contraindication to the use of a gracilis muscle flap in reconstructive surgery in those cases where it is used to repair a soft-tissue defect without functional reconstruction. Conversely, in situations when functional reconstruction is expected, care should be taken in the selection of this reconstructive option as intramuscular fat deposition results in reduced muscle quality and force (24).

In our series, we found a moderate negative correlation between gracilis muscle mass and age. Many studies have investigated the reasons for muscle mass decrease in elderly patients, with a special focus on the causes of sarcopenia (2126). The multifactorial etiology includes environmental causes, disease triggers, activation of inflammatory pathways, mitochondrial abnormalities, loss of neuromuscular junctions, reduction of satellite cell numbers, and hormonal changes (22).

We chose to examine the mass of gracilis in relation to patient height, weight, age, and BMI as these parameters are routinely recorded prior to surgery, without further cost, time, or radiation risk for the patient. In fact, the variables that we tested can be very easily collected during the preoperative evaluation of the patient, helping the surgeon in making a correct decision among the several reconstructive options.

In conclusion, we observed a low rate of complications in our series. In all cases, the anastomoses were made outside the zone of injury and the vascular status of the lower extremity was accurately investigated prior to surgery. Proper vessel selection at the recipient site, which in our cases was equally represented by anterior and posterior tibialis vessels, represented a key aspect for the success of the reconstruction of the lower extremity (27).

\section{Conclusion}

Patient height, weight, BMI and age were proven to be reliable predictors of gracilis muscle mass. This will help surgeons in estimating the suitability of this reconstructive option for their specific case.

\section{Founding}

None.

\section{Conflicts of Interest}

None.

\section{References}

1 Harii K, Ohmori K and Sekiguchi J: The free musculocutaneous flap. Plast Reconstr Surg 57: 294-303, 1976.

2 Calabrese L, Saito A, Navach V, Bruschini R, Saito N, Zurlo V, Ostuni A and Garusi C: Tongue reconstruction with the gracilis myocutaneous free flap. Microsurg 31: 355-359, 2011.

3 Harii $\mathrm{K}$, Ohmori $\mathrm{K}$ and Torii $\mathrm{S}$ : Free gracilis muscle transplantation, with microneurovascular anastomoses for the treatment of facial paralysis. A preliminary report. Plast Reconstr Surg 57: 133-143, 1976.

4 Wechselberger G, Schoeller T, Bauer T, Schwabegger A, Ninkovic M, Rainer C and Ninkovic M: Surgical technique and clinical application of the transverse gracilismyocutaneous free flap. Br J Plast Surg 54: 423-427, 2001. 
5 McCraw JB, Massey FM, Shanklin KD and Horton CE: Vaginal reconstruction with gracilis myocutaneous flaps. Plast Reconstr Surg 58: 176-183, 1976.

6 Vyas RM and Pomahac B: Use of a bilobed gracilis myocutaneous flap in perineal and genital reconstruction. Ann Plast Surg 65: 225-227, 2010.

7 Yousif NJ, Matloub HS, Kolachalam R, Grunert BK and Sanger JR: The transverse gracilis musculocutaneous flap. Ann Plast Surg 29: 482-490, 1992.

8 Yousif NJ: The transverse gracilis musculocutaneous flap. Ann Plast Surg 31: 382, 1993.

9 Arnez ZM, Pogorelec D, Planinsek F and Ahcan U: Breast reconstruction by the free transverse gracilis (TUG) flap. Br J Plast Surg 57: 20-26, 2004.

10 Schoeller T, Wechselberger G, Hussl H, Otto-Schoeller A, Bauer $\mathrm{T}$ and Piza-Katzer $\mathrm{H}$ : Aesthetic improvements in endoscopic gracilis muscle harvest through a single transverse incision in the groin crease. Plast Reconstr Surg 110: 218-221, 2002.

11 Tremp M, Wettstein R, Raffoul W, Schaefer DJ and Kalbermatten DF: Secret scar free gracilis flap. J Reconstr Microsurg 28: 341-344, 2012.

12 Reddy V and Stevenson TR: MOC-PS(SM) CME article: lower extremity reconstruction. Plast Reconstr Surg 121: 1-7, 2008.

13 Reece GP and Kroll SS: Abdominal wall complications. Prevention and treatment. Clin Plast Surg 25: 235-249, 1998.

14 Redett RJ, Robertson BC, Chang B, Girotto J and Vaughan T: Limb salvage of lower-extremity wounds using free gracilis muscle reconstruction. Plast Reconstr Surg 106: 1507-1513, 2000.

15 Khoo A, Rosich-Medina A, Woodham A, Jessop ZM, Di Candia $\mathrm{M}$ and Malata CM: The relationship between the intercostal distance, patient height and outcome in microsurgical breast reconstruction using the second interspace rib-sparing internal mammary vessel exposure. Microsurg 34: 448-453, 2014.

16 Bhavna and Nath S: Estimation of Stature on the Basis of Measurements of the Lower Limb. Anthropol Spec Vol 3: 219222, 2007
17 Hauser R, Smoliński J and Gos T: The estimation of stature on the basis of measurements of the femur. Forensic Sci Int 147: 185-190, 2005.

18 Sanli SG, Kizilkanat ED, Boyan N, Ozsahin ET, Bozkir MG, Soames R, Erol H and Oguz O: Stature estimation based on hand length and foot length. Clin Anat 18: 589-596, 2005.

19 Heymsfield SB, Adamek M, Gonzalez MC, Jia G and Thomas DM: Assessing skeletal muscle mass: historical overview and state of the art. J Cachexia Sarcopenia Muscle 5: 9-18, 2014.

20 Webster JD, Hesp R and Garrow JS: The composition of excess weight in obese women estimated by body density, total body water and total body potassium. Hum Nutr Clin Nutr 38: 299-306, 1984.

21 Forbes GB: Human body composition: growth, aging, nutrition, and activity. New York, Springer-Verlag, pp. 28-49, 1987.

22 Walston JD: Sarcopenia in older adults. Curr Opin Rheumatol 24: 623-627, 2012.

23 Rahemi H, Nigam $\mathrm{N}$ and Wakeling JM: The effect of intramuscular fat on skeletal muscle mechanics: implications for the elderly and obese. J R Soc Interface 12: 20150365, 2015.

24 Akazawa N, Okawa N, Tamura K and Moriyama H: Relationships between intramuscular fat, muscle strength and gait independence in older women: A cross-sectional study. Geriatr Gerontol Int 17: 1683-1688, 2017.

25 Siglinsky E, Krueger D, Ward RE, Caserotti P, Strotmeyer ES, Harris TB, Binkley N and Buehring B: Effect of age and sex on jumping mechanography and other measures of muscle mass and function. J Musculoskelet Neuronal Interact 15: 301-308, 2015.

26 Ko MJ, Yun S, Oh K and Kim K: Relation of serum 25hydroxyvitamin D status with skeletal muscle mass by sex and age group among Korean adults. Br J Nutr 114: 1838-1844, 2015.

27 Park S, Han SH and Lee TJ: Algorithm for recipient vessel selection in free tissue transfer to the lower extremity. Plast Reconstr Surg 103: 1937-1948, 1999.

Received January 30, 2018

Revised March 8, 2018

Accepted March 15, 2018 